\title{
Strategies of temozolomide in future glioblastoma treatment
}

This article was published in the following Dove Press journal:

OncoTargets and Therapy

9 January 2017

Number of times this article has been viewed

\author{
Chooi Yeng Lee \\ School of Pharmacy, Monash \\ University Malaysia, Selangor, \\ Malaysia
}

Correspondence: Chooi Yeng Lee School of Pharmacy, Monash University Malaysia, Jalan Lagoon Selatan, 47500 Bandar Sunway, Selangor, Malaysia

Tel +60355146314

Fax +60355146364

Email chooi.yeng.lee@monash.edu

\begin{abstract}
Glioblastoma multiforme (GBM) may be one of the most challenging brain tumors to treat, as patients generally do not live more than 2 years. This review aimed to give a timely review of potential future treatments for GBM by looking at the latest strategies, involving mainly the use of temozolomide (TMZ). Although these studies were carried out either in vitro or in rodents, the findings collectively suggested that we are moving toward developing a more efficacious therapy for GBM patients. Nanoparticles preparation was, by far, the most extensively studied strategy for targeted brain delivery. Therefore, the first section of this review presents a treatment strategy using TMZ-loaded nanocarriers, which encompassed nanoparticles, nanoliposomes, and nanosponges. Besides nanocarriers, new complexes that were formed between TMZ and another chemical agent or molecule have shown increased cytotoxicity and antitumor activity. Another approach was by reducing GBM cell resistance to TMZ, and this was achieved either through the suppression of metabolic change occurring in the cells, inhibition of the DNA repair protein, or up-regulation of the protein that mediates autophagy. Finally, the review collates a list of substances that have demonstrated the ability to suppress tumor cell growth.
\end{abstract}

Keywords: cellular resistance, glioblastoma multiforme, nanoparticles, targeted delivery, temozolomide

\section{Introduction}

Glioblastoma multiforme (GBM) is one of the most common primary brain tumors, and the standard treatment for this begins with surgical resection of the tumor. Thereafter, patients undergo radiotherapy (RT) and concomitantly receive Temodal ${ }^{\circledR}$ (temozolomide, TMZ; Merck \& Co., Inc., Whitehouse Station, NJ, USA) followed by adjuvant TMZ therapy. This treatment regimen is, by far, the most effective as it increases the median overall survival from 12 months (with RT alone) to 14.6 months, and the percentage of patients alive at 2 years increases from $10.4 \%$ to $26.5 \%{ }^{1}$

$\mathrm{TMZ}$ is an alkylating agent which breaks the DNA double-strand, thus causing cell cycle arrest and ultimately cell death. However, due to its short half-life, TMZ is administered at high dose, and prolonged systemic administration has resulted in a series of side effects. ${ }^{2}$ As a means to improve the efficacy of TMZ and reduce the side effects of chemotherapy, systemic TMZ administration using a biodegradable carrier such as nanoparticles is widely studied. ${ }^{3}$

Since the nanoparticles allow targeted drug delivery, the preparation may reduce the administrative dose. Research, to date, has focused on preparing nanoparticles that possess several properties, such as enhanced ability to reach the brain, cross the bloodbrain barrier, and bind specifically to receptors that are over-expressed in glioma cells. Moreover, as GBM cells are infiltrative in nature, the therapeutic efficacy of a drug or formulation may be improved by reversing the pathophysiological changes that occur 
at the intracellular level. One of the most established strategies attempted to address this challenge was by modulation of the molecular mechanism that has caused GBM cells to be resistant to TMZ. This review presents recent publications that described, firstly, nanocarriers and TMZ-conjugated compounds that were synthesized for targeted brain delivery. This is followed by strategies to increase the sensitivity of GBM cells to TMZ therapy, and finally, a list of selected chemical agents that have shown effectiveness in the suppression of tumor cell growth and migration.

\section{TMZ-loaded nanocarriers}

Biodegradable polymer is one of the most extensively used materials in pharmaceutical research. It shows better stability in biological fluids, thereby enhancing the delivery of the drug that it carries to the target site. Because of its versatility and acceptable safety profile, poly(D,L-lactide-co-glycolide) (PLGA) has been widely used in the fabrication of TMZ nanoparticles. By using the solvent diffusion technique, TMZ loaded in PLGA nanoparticles showed a 30\% burst release in the initial 2 hours, and subsequently a sustained release of up to 120 hours. The PLGA nanoparticles displayed cytotoxic effect on $\mathrm{C} 6$ glioma cells comparable to that of the free TMZ, and poloxamer 80 that was coated on these nanoparticles increased cellular uptake of the nanoparticles. ${ }^{4}$ In another study, which also used the emulsifying solvent evaporation method, superparamagnetic iron oxide was incorporated into the polysorbate 80 -coated PLGA nanoparticles. There was no burst release in this preparation and $90 \%$ of TMZ was released over a long period of 21 days. The nanoparticles also exerted a dose-dependent effect on C6 glioma cells, and were more potent than the free TMZ in suppressing cell growth. The polysorbate 80-coated nanoparticles showed better cellular uptake than the non-coated nanoparticles. Furthermore, the presence of iron oxide enabled the nanoparticles to be tracked by magnetic resonance imaging (MRI). ${ }^{5}$ These studies showed that the surfactant allowed a slow release of TMZ from the PLGA nanoparticles, as well as increased the uptake of the particles by GBM cells.

Nanocarriers that demonstrate in vivo efficacy, that is, having altogether the ability to cross the blood-brain barrier and target the glioma cells, and overcome GBM cell resistance to TMZ, may be an ideal preparation. A nanocarrier nearly meeting those criteria was reported recently. ${ }^{6}$ In that study, a chitosan-TMZ-biotin conjugate was encapsulated into nanoparticles conjugated with chlorotoxin. The nanoparticles markedly improved the stability of TMZ in both acidic and neutral $\mathrm{pH}$. The conjugation of chlorotoxin on the surface of the nanoparticles increased cellular uptake and accumulation of the nanoparticles in the GBM cell lines, and these effects correlated with a reduction of half maximal inhibitory concentration $\left(\mathrm{IC}_{50}\right)$ of $\mathrm{TMZ}$ or a higher rate of apoptosis. Importantly, the nanoparticles injected intravenously into mice crossed an intact blood-brain barrier, suggesting potential in vivo anticancer effects.

TMZ-loaded nanoparticles have also been designed to simultaneously act on microRNA (miRNA). miRNA is a short, non-coding RNA molecule that regulates gene expression by repressing the translation process or inducing the cleavage of target RNA transcripts. Abnormal expression of miRNA was associated with tumor progression and therapeutic drug resistance. ${ }^{7}$ miR221 was up-regulated in gliomas, ${ }^{8}$ and miR221 down-regulation sensitized the cells to the effect of TMZ. ${ }^{9}$ Bertucci et $\mathrm{al}^{10}$ synthesized TMZloaded mesoporous silica nanoparticles with the surface of the particles decorated with a polyarginine-peptide nucleic acid conjugate that targets the miR221. The nanosystem was rapidly taken up by the C6 and T98G glioma cells, which potently induced apoptosis in the resistant glioma cells. Therefore, this nanoparticles preparation has not only promoted the entry of TMZ into the cells but also addressed the issue pertaining to glioma cells sensitivity.

Apart from oral and parenteral administration, TMZ may be directly implanted to the tumor site. Convection-enhanced delivery (CED) via catheters implanted during surgery uses a hydrostatic pressure gradient to distribute the drug through brain tissues. CED can not only increase the distribution volume of the infused macromolecules but also cause unpredictable distribution. Bernal and co-workers ${ }^{11}$ attempted to overcome random drug distribution by using a post-infusion imaging technique. They incorporated iron oxide into the polymeric nanoparticles, and through CED, tracked the nanoparticles distribution by MRI. This method effectively reduced the growth of glioma xenograft and extended animal survival.

Besides polymeric nanoparticles, polymeric nanoliposomes have been prepared with TMZ and quercetin as the payload. ${ }^{12}$ The surface of the liposomes was further coated with surfactant 1,2-distearoyl-sn-glycero-3-phosphoethanolamine-N-[methoxy(polyethylene glycol)-2000] (DSPE-PEG2000) to increase the blood residence time of the liposomes. Quercetin and TMZ combination was seen to be more potent than the free TMZ and quercetin-loaded nanoparticles in reducing the viability of U87 and TMZresistant U87/TR cells. In vivo, the quercetin/TMZ liposomes accumulated in the brain, whereas the free TMZ and quercetin nanoparticles accumulated in other organs, such as kidneys 
and heart. However, there are no data yet with regards to the in vivo antitumor effects of the quercetin/TMZ liposomes.

Nanosponges are highly porous, hyperbranched cyclodextrin (CD)-based polymers that form a nanosuspension upon dispersion in water. ${ }^{13}$ The CD-based nanosponges are a relatively new class of polymers which have been extensively used as a carrier for anticancer treatment. TMZ was among the drugs investigated. TMZ was slowly released from the nanosponges and showed comparable cytotoxicity as the free TMZ. These nanosponges also induced morphological changes in the U-373 glioma cell lines. ${ }^{14}$ Nonetheless, more extensive studies are necessary to explore the potential of nanosponges, particularly the advantage of their use over polymeric nanoparticles since the latter is already a wellestablished drug carrier.

Overall, we can anticipate that TMZ-loaded nanocarriers will remain a popular strategy to improve the treatment efficacy and prolong the survival of GBM patients. Surfacefunctionalized nanoparticles, those that carry more than one drug or molecule, and other elegantly designed nanocarriers will continue to be reported. However, nanoparticles or pharmaceutical preparation are by no means the only approaches that we can rely on for GBM treatment.

\section{TMZ-conjugated compounds}

As cited earlier in this review, TMZ was conjugated with chitosan and biotin to increase the biological effects of TMZ. ${ }^{6}$ The rationale behind the conjugation was that chitosan could interact with cell surface macromolecules and increase cellular uptake, ${ }^{15}$ while biotin increases the stability of a compound against digestive enzymes. ${ }^{16}$ We can therefore anticipate that the chitosan-TMZ-biotin conjugate without encapsulation into nanoparticles is equally beneficial.

In addition to chitosan and biotin, conjugation between $\mathrm{TMZ}$ and non-natural resources has been done. TMZ together with perillyl alcohol formed a new complex NEO212 that was more cytotoxic than TMZ on the glioma cancer stem cells (GSCs). ${ }^{17} \mathrm{NEO} 212$ introduced into the culture medium containing GSCs induced 50\% cell death after 72 hours of incubation, and interestingly, the dose of NEO212 was 7-40 fold lower than that of the TMZ. The sphere-forming assay performed on proneural GSCs indicated that NEO212 was 10-fold more potent than TMZ, and the induction of DNA damage in GSCs was independent of $O^{6}$-methylguanineDNA-methyltransferase (MGMT). ${ }^{17}$ In another study, TMZ was conjugated with 5-nitro-2-(3-phenylpropylamino)benzoate (NPPB), a non-specific chloride channel blocker. ${ }^{18}$ Chloride channel in glioma cells mediates the change in cell volume and shape, thereby regulating cell migration and invasion. NPPB alone suppressed the effects of chloride channel, and the TMZ-NPPB conjugate acted as both a DNA alkylating agent and a suppressant in the proliferation and migration of glioma cells. ${ }^{18}$ Clearly, TMZ combines with the right molecule that improves the potency of TMZ as the complex molecules reduce GBM cell resistance, and/or act synergistically in preventing GBM cell growth.

\section{Sensitization of glioma cells to TMZ}

This strategy targets the modulation of the specific mechanism that contributes to cell resistance. One of the known causes of resistance is alteration in cellular metabolism, in which glioma cells use aerobic glycolysis instead of oxidative phosphorylation to generate energy. An indication of metabolic alteration is the increased expression of tumor necrosis factor receptor-associated protein 1 (TRAP1) in the mitochondria. ${ }^{19}$ Cells over-expressing TRAP1 were found to be resistant to chemotherapeutic agents. ${ }^{20}$ In GBM cell lines and GBM specimens obtained from human subjects, knocking down the TRAP1 effectively inhibited tumor growth and migration and enhanced the therapeutic effects of TMZ. ${ }^{21}$

Another cause of reduced cellular sensitivity is the presence of MGMT. The DNA repair protein, MGMT, transforms the naturally occurring DNA lesion $O^{6}$-methylguanine to guanine, while the methyl group is transferred to cysteine. MGMT "unfortunately" also repairs the damage caused by DNA alkylating agents, hence contradicts the action of TMZ. A successful synthesis of MGMT inhibitor, as found in the literature recently, was AA-CW236. ${ }^{22}$ AA-CW236 showed a high degree of selectivity toward MGMT, and in combination with TMZ, the complex has a sensitization effect on breast and colon cancer cell lines. Based on these studies, TMZ/AA-CW236 may work favorably on glioma cells.

Autophagy is a process where cellular proteins and organelles are engulfed by autophagosomes before these entities are delivered to lysosomes. The process is required to maintain cellular homeostasis and genomic integrity. ${ }^{23}$ The level of autophagy was decreased in GBM, ${ }^{24}$ and treatment with TMZ reversed the change. ${ }^{25,26}$ Therefore, it is important to maintain autophagy, especially in malignant tissues. ER membrane protein complex subunit 6 (EMC6) is a protein expressed on the outer membrane of the endoplasmic reticulum (ER). In vitro, EMC6 enhanced autophagy in GBM cells by down-regulating the phosphatidylinositol-3-kinase (PIK3CA)/protein kinase B (AKT) and the mammalian target of rapamycin (mTOR) pathways. In vivo, EMC6 that was over-expressed increased the sensitivity of GBM cells 
to TMZ treatment, and it suppressed GBM proliferation via the induction of autophagy. ${ }^{27}$ In summary, recent strategies to address GBM cell resistance include down-regulation of TRAP1, the use of selective MGMT inhibitor, and upregulation of EMC6.

\section{Other therapeutic agents}

Even though TMZ is the main drug choice for GBM treatment, other therapeutic agents have been explored, and they range from clinically used anti-epileptic drug (AED) to antibodies and plant source. AED was used because GBM patients may develop seizures as their disease progresses. Moreover, in GBM patients who also presented with epileptic seizures, valproic acid in combination with total tumor resection and postoperative chemotherapy led to a better prognosis of GBM. ${ }^{28}$ Oxcarbazepine inhibited cell growth at therapeutic concentration in vitro. However, as a pro-drug, oxcarbazepine was rapidly metabolized and its metabolites did not inhibit cell growth. Therefore, oxcarbazepine may only be useful as an anticancer agent if it is administered locally or systemically. ${ }^{29}$

Cucurmin, a bioactive compound derived from Indian spice Cucurmin longa (C. longa), is a well-known antioxidant and anticancer agent. It modulates cell proliferation and apoptosis via a number of signaling pathways, and detailed action of cucurmin was recently reviewed..$^{30}$ Of note, cucurmin crossed the blood-brain barrier ${ }^{31}$ and reduced the tumor size. ${ }^{32-34}$ The effect of cucurmin was enhanced when it was administered together with a phospholipase $A_{2}$ alpha inhibitor, which acts by inhibiting the formation of lipid droplets in glioma cells. ${ }^{35}$

An interesting approach is the use of antibodies nimotuzumab and bevacizumab to block the effect of epidermal growth factor receptor (EGFR) vIII, a mutated EGFR. EGFRvIII is expressed in glioma cells and not in normal tissues, where it enhances tumorigenicity and drug resistance. ${ }^{36}$ Nimotuzumab has been used alone or concurrently with $\mathrm{RT}$ in recurrent or relapsed brain tumors. ${ }^{37,38}$ In mice, nimotuzumab enhanced the effect of TMZ in suppressing the growth of EGFRvIII-expressed glioma cells. ${ }^{39}$ Meanwhile, bevacizumab acts by blocking the vascular EGFR pathway, thereby preventing vascularization and edema. The effects of combining bevacizumab and TMZ in the treatment of newly diagnosed GBM and recurrent GBM, as well as the adverse effects of bevacizumab, were recently reviewed. ${ }^{40}$ But it is not conclusive that bevacizumab is beneficial for GBM.

Zoledronic acid (ZOL) is an aminobisphosphonate that has antitumor activity. ${ }^{41}$ Because of its short serum half-life, ZOL nanoparticles were prepared. ${ }^{42}$ These nanoparticles were synthesized by mixing the transferrin-PEGylated liposomes

Table I A summary of recent publications that used nanocarriers in attempts to improve the efficacy of TMZ

\begin{tabular}{|c|c|c|c|c|c|c|}
\hline $\begin{array}{l}\text { Main } \\
\text { challenges } \\
\text { addressed }\end{array}$ & $\begin{array}{l}\text { TMZ-loaded } \\
\text { PLGA NPs } \\
\text { (poloxomer 80- } \\
\text { or polysorbate } \\
80 \text {-coated) }\end{array}$ & $\begin{array}{l}\text { Chitosan/ } \\
\text { TMZ/biotin- } \\
\text { loaded NPs } \\
\text { coated with } \\
\text { chlorotoxin }\end{array}$ & $\begin{array}{l}\text { TMZ-loaded } \\
\text { mesoporous } \\
\text { silica NPs } \\
\text { decorated with a } \\
\text { PPNAC targeting } \\
\text { miR22 I } 10\end{array}$ & $\begin{array}{l}\text { TMZ-loaded } \\
\text { polymeric NPs } \\
\text { incorporated } \\
\text { with iron oxide, } \\
\text { and delivered } \\
\text { by CED"I }\end{array}$ & $\begin{array}{l}\text { TMZ/quercetin- } \\
\text { loaded } \\
\text { nanoliposomes } \\
\text { coated with } \\
\text { DSPE-PEG2000'2 }\end{array}$ & $\begin{array}{l}\text { TMZ-loaded } \\
\text { cyclodextrin- } \\
\text { based } \\
\text { nanosponges' }\end{array}$ \\
\hline $\begin{array}{l}\text { Crossing the } \\
\text { blood-brain } \\
\text { barrier }\end{array}$ & & $\checkmark$ & & & & \\
\hline $\begin{array}{l}\text { Targeted } \\
\text { delivery to the } \\
\text { tumor site in } \\
\text { rodents }\end{array}$ & & & & $\checkmark$ & $\checkmark$ & \\
\hline $\begin{array}{l}\text { Tissue } \\
\text { resistance } \\
\text { (tested on cell } \\
\text { line) }\end{array}$ & & $\checkmark$ & $\checkmark$ & & $\checkmark$ & \\
\hline $\begin{array}{l}\text { Cellular uptake } \\
\text { (tested on } \\
\text { GBM cell line) }\end{array}$ & $\checkmark$ & $\checkmark$ & $\checkmark$ & & & $\checkmark$ \\
\hline $\begin{array}{l}\text { In vivo } \\
\text { suppression of } \\
\text { tumor growth }\end{array}$ & & & & $\checkmark$ & & \\
\hline
\end{tabular}

Abbreviations: CED, convection-enhanced delivery; DSPE-PEG2000, I,2-distearoyl-sn-glycero-3-phosphoethanolamine-N-[methoxy(polyethylene glycol)-2000]; GBM, glioblastoma multiforme; NPs, nanoparticles; PLGA, poly(D,L-lactide-co-glycolide); PPNAC, polyarginine-peptide nucleic acid conjugate; TMZ, temozolomide. 
Table 2 A summary of TMZ conjugates and non-TMZ compounds that are promising for GBM treatment

\begin{tabular}{|c|c|c|c|c|c|c|}
\hline $\begin{array}{l}\text { Main } \\
\text { challenges } \\
\text { addressed }\end{array}$ & $\begin{array}{l}\text { TMZ conjugates } \\
\text { (TMZ/POH and } \\
\text { TMZ/NPPB) }{ }^{17,18}\end{array}$ & $\begin{array}{l}\text { Down-regulation } \\
\text { of TRAPI, } \\
\text { and MGMT } \\
\text { inhibitor }{ }^{21,22}\end{array}$ & $\begin{array}{l}\text { Up-regulation } \\
\text { of EMC6 }{ }^{27}\end{array}$ & Cucurmin ${ }^{31-34}$ & $\begin{array}{l}\text { Nimotuzumab/ } \\
\text { TMZ } \\
\text { combination }^{39}\end{array}$ & $\begin{array}{l}\text { ZOL-loaded } \\
\text { transferrin- } \\
\text { PEGylated } \\
\text { nanoparticles }{ }^{42}\end{array}$ \\
\hline $\begin{array}{l}\text { Crossing the } \\
\text { blood-brain } \\
\text { barrier }\end{array}$ & & & & $\checkmark$ & & $\checkmark$ \\
\hline $\begin{array}{l}\text { Targeted } \\
\text { delivery to } \\
\text { the tumor site } \\
\text { in rodent }\end{array}$ & & & & & & $\checkmark$ \\
\hline $\begin{array}{l}\text { Tissue } \\
\text { resistance } \\
\text { (tested on cell } \\
\text { line) }\end{array}$ & $\checkmark$ & $\checkmark$ & $\checkmark$ & & & \\
\hline $\begin{array}{l}\text { Cellular } \\
\text { uptake (tested } \\
\text { on GBM cell } \\
\text { line) }\end{array}$ & & & & & & \\
\hline $\begin{array}{l}\text { In vivo } \\
\text { suppression of } \\
\text { tumor growth }\end{array}$ & & & $\checkmark$ & $\checkmark$ & $\checkmark$ & $\checkmark$ \\
\hline
\end{tabular}

Abbreviations: EMC6, ER membrane protein complex subunit 6; GBM, glioblastoma multiforme; MGMT, O6-methylguanine-DNA-methyltransferase; NPPB, 5-nitro-2(3-phenylpropylamino)-benzoate; POH, perillyl alcohol; TMZ, temozolomide; TRAPI, tumor necrosis factor receptor-associated protein I; ZOL, zoledronic acid.

and the calcium phosphate nanoparticles incorporated with ZOL. These nanoparticles were slightly more toxic than the free ZOL, but were three times more toxic than TMZ in the U373MG-LUC cell line. Nanoparticles that were conjugated with transferrin also compared favorably against nontransferrin-conjugated ZOL nanoparticles for their ability to cross the blood-brain barrier, accumulate in the brain of mice bearing the tumor, and inhibit tumor growth.

Together, cucurmin, nimotuzumab, and ZOL are promising alternates to TMZ in the treatment of GBM. It is worth mentioning that ZOL was administered as nanoparticles, which suggested again that nanocarriers may have additional advantage over other substances for targeted brain delivery. Tables 1 and 2 summarize the therapeutic strategies presented in this review.

\section{Conclusion}

It is quite clear that there is no end to novelty and creativity in the development of new therapeutic agents to prolong the survival and improve the quality of life of GBM patients. At the same time, we may not be able to specify which approach stood out among these strategies, especially as all the preparations are still at the pre-clinical testing stage. But combined strategies such as using glioma cell-targeted nanocarrier and the strategy that tackles GBM cell resistance may be most beneficial, as the method will reduce the therapeutic dose, thus the risk of side effects, provide better patient compliance, and prevent resistance to treatment.

\section{Disclosure}

The author reports no conflicts of interest in this work.

\section{References}

1. Stupp R, Mason WP, van den Bent MJ, et al; European Organisation for Research and Treatment of Cancer Brain Tumor and Radiotherapy Groups; National Cancer Institute of Canada Clinical Trials Group. Radiotherapy plus concomitant and adjuvant temozolomide for glioblastoma. $N$ Engl J Med. 2005;352(10):987-996.

2. Zhang H, Gao S. Temozolomide/PLGA microparticles and antitumor activity against glioma C6 cancer cells in vitro. Int J Pharm. 2007; 329(1-2):122-128.

3. Tian XH, Lin XN, Wei F, et al. Enhanced brain targeting of temozolomide in polysorbate- 80 coated polybutylcyanoacrylate nanoparticles. Int J Nanomedicine. 2011;6:445-452.

4. Jain DS, Athawale RB, Bajaj AN, et al. Unraveling the cytotoxic potential of temozolomide loaded into PLGA nanoparticles. Daru. 2014; 22(1): 18 .

5. Ling Y, Wei K, Zou F, Zhong S. Temozolomide loaded PLGA-based superparamagnetic nanoparticles for magnetic resonance imaging and treatment of malignant glioma. Int J Pharm. 2012;430(1-2):266-275.

6. Fang C, Wang K, Stephen ZR, et al. Temozolomide nanoparticles for targeted glioblastoma therapy. ACS Appl Mater Interfaces. 2015; 7(12):6674-6682.

7. Calin GA, Croce CM. MicroRNA signatures in human cancers. Nat Rev Cancer. 2006;6(11):857-866.

8. Zhang J, Han L, Ge Y, et al. miR-221/222 promote malignant progression of glioma through activation of the Akt pathway. Int $J$ Oncol. 2010;36(4):913-920.

9. Chen L, Zhang J, Han L, et al. Downregulation of miR-221/222 sensitizes glioma cells to temozolomide by regulating apoptosis independently of p53 status. Oncol Rep. 2012;27(3):854-860. 
10. Bertucci A, Prasetyanto EA, Septiadi D, et al. Combined delivery of temozolomide and anti-miR221 PNA using mesoporous silica nanoparticles induces apoptosis in resistant glioma cells. Small. 2015; 11(42):5687-5695.

11. Bernal GM, LaRiviere MJ, Mansour N, et al. Convection-enhanced delivery and in vivo imaging of polymeric nanoparticles for the treatment of malignant glioma. Nanomedicine. 2014;10(1):149-157.

12. Hu J, Wang J, Wang G, Yao Z, Dang X. Pharmacokinetics and antitumor efficacy of DSPE-PEG2000 polymeric liposomes loaded with quercetin and temozolomide: analysis of their effectiveness in enhancing the chemosensitization of drug-resistant glioma cells. Int J Mol Med. 2016;37(3):690-702.

13. Swaminathan S, Cavalli R, Trotta F. Cyclodextrin-based nanosponges: a versatile platform for cancer nanotherapeutics development. Wiley Interdiscip Rev Nanomed Nanobiotechnol. 2016;8(4):579-601.

14. Jain D, Gursalkar T, Bajaj A. Nanosponges of an anticancer agent for potential treatment of brain tumors. Am J Neuroprot Neuroregen. 2013; 5(1):32-43.

15. Ma PL, Buschmann MD, Winnik FM. One-step analysis of DNA/ chitosan complexes by field-flow fractionation reveals particle size and free chitosan content. Biomacromolecules. 2010;11(3):549-554.

16. Chae SY, Jin CH, Shin HJ, Youn YS, Lee S, Lee KC. Preparation, characterization, and application of biotinylated and biotin-PEGylated glucagon-like peptide-1 analogues for enhanced oral delivery. Bioconjug Chem. 2008;19(1):334-341.

17. Jhaveri N, Agasse F, Armstrong D, et al. A novel drug conjugate, NEO212, targeting proneural and mesenchymal subtypes of patientderived glioma cancer stem cells. Cancer Lett. 2016;371(2):240-250.

18. Park M, Song C, Yoon H, Choi KH. Double blockade of glioma cell proliferation and migration by temozolomide conjugated with NPPB, a chloride channel blocker. ACS Chem Neurosci. 2016;7(3):275-285.

19. Yoshida S, Tsutsumi S, Muhlebach G, et al. Molecular chaperone TRAP1 regulates a metabolic switch between mitochondrial respiration and aerobic glycolysis. Proc Natl Acad Sci U S A. 2013;110(17): E1604-E1612.

20. Constantino E, Maddalena F, Calise S, et al. TRAP1, a novel mitochondrial chaperone responsible for multi-drug resistance and protection from apoptosis in human colorectal carcinoma cells. Cancer Lett. 2009;279(1):39-46.

21. Wu J, Liu Y, Cho K, et al. Downregulation of TRAP1 sensitizes glioblastoma cells to temozolomide chemotherapy through regulating metabolic reprogramming. Neuroreport. 2016;27(3):136-144.

22. Wang C, Abegg D, Hoch DG, Adibekian A. Chemoproteomics-enabled discovery of a potent and selective inhibitor of the DNA repair protein MGMT. Angew Chem Int Ed Engl. 2016;55(8):2911-2915.

23. Maiuri MC, Kroemer G. Autophagy in stress and disease. Cell Death Differ. 2015;22(3):365-366.

24. Huang X, Bai HM, Chen L, Li B, Lu YC. Reduced expression of LC3B-II and Beclin 1 in glioblastoma multiforme indicates a downregulated autophagic capacity that relates to the progression of astrocytic tumors. J Clin Neurosci. 2010;17(12):1515-1519.

25. Noack J, Choi J, Richter K, Kopp-Schneider A, Régnier-Vigouroux A. A sphingosine kinase inhibitor combined with temozolomide induces glioblastoma cell death through accumulation of dihydrosphingosine and dihydroceramide, endoplasmic reticulum stress and autophagy. Cell Death Dis. 2014;5:e1425.

OncoTargets and Therapy

\section{Publish your work in this journal}

OncoTargets and Therapy is an international, peer-reviewed, open access journal focusing on the pathological basis of all cancers, potential targets for therapy and treatment protocols employed to improve the management of cancer patients. The journal also focuses on the impact of management programs and new therapeutic agents and protocols on
26. Kanzawa T, Germano IM, Komata T, Ito H, Kondo Y, Kondo S. Role of autophagy in temozolomide-induced cytotoxicity for malignant glioma cells. Cell Death Differ. 2004;11(4):448-457.

27. Shen X, Kan S, Hu J, et al. EMC6/TMEM93 suppresses glioblastoma proliferation by modulating autophagy. Cell Death Dis. 2016; 7:e2043.

28. Tsai HC, Wei KC, Tsai CN, et al. Effect of valproic acid on the outcome of glioblastoma multiforme. Br J Neurosurg. 2012;26(3):347-354.

29. Lee CY, Lai HY, Chiu A, Chan SH, Hsiao LP, Lee ST. The effects of antiepileptic drugs on the growth of glioblastoma cell lines. J Neurooncol. 2016;127(3):445-453.

30. Luthra PM, Lal N. Prospective of cucurmin, a pleiotropic signallling molecule from Cucurma longa in the treatment of Glioblastoma. Eur J Med Chem. 2016;109:23-35.

31. Purkayastha S, Berliner A, Fernando SS, et al. Cucurmin blocks brain tumor formation. Brain Res. 2009;1266:130-138.

32. Aoki H, Takada Y, Kondo S, Sawaya R, Aggarwal BB, Kondo Y. Evidence that cucurmin suppresses the growth of malignant gliomas in vitro and in vivo through induction of autophagy: role of Akt and extracellular signal-regulated kinase signaling pathways. Mol Pharmacol. 2007;72(1):29-39.

33. Zhuang $\mathrm{W}$, Long $\mathrm{L}$, Zheng $\mathrm{B}$, et al. Cucurmin promotes differentiation of glioma-initiating cells by inducing autophagy. Cancer Sci. 2012; 103(4):684-690.

34. Perry MC, Demeule M, Régina A, Moumdjian R, Béliveau R. Cucurmin inhibits tumor growth and angiogenesis in glioblastoma xenografts. Mol Nutr Food Res. 2010;54(8):1192-1201.

35. Zhang I, Cui Y, Amiri A, Ding Y, Campbell RE, Maysinger D. Pharmacological inhibition of lipid droplet formation enhances the effectiveness of cucurmin in glioblastoma. Eur J Pharm Biopharm. 2016; 100:66-76.

36. Schlegel J, Merdes A, Stumm G, et al. Amplification of the epidermalgrowth-factor-receptor gene correlates with different growth behaviour in human glioblastoma. Int J Cancer. 1994;56(1):72-77.

37. Ramos TC, Figueredo J, Catala M, et al. Treatment of high-grade glioma patients with the humanized anti-epidermal growth factor receptor (EGFR) antibody h-R3: report from a phase I/II trial. Cancer Biol Ther. 2006;5(4):375-379.

38. Solomón MT, Selva JC, Figueredo J, et al. Radiotherapy plus nimotuzumab or placebo in the treatment of high grade glioma patients: results from a randomized, double blind trial. BMC Cancer. 2013;13:299.

39. Nitta Y, Shimizu S, Shishido-Hara Y, Suzuki K, Shiokawa Y, Nagane M. Nimotuzumab enhances temozolomide-induced growth suppression of glioma cells expressing mutant EGFR in vivo. Cancer Med. 2016;5(3):486-499.

40. Narita Y. Bevacizumab for glioblastoma. Ther Clin Risk Manag. 2015; 11:1759-1765.

41. Caraglia M, Budillon A, Tagliaferri P, Marra M, Abbruzzese A, Caponigro F. Isoprenylation of intracellular proteins as a new target for the therapy of human neoplasms: preclinical and clinical implications. Curr Drug Targets. 2005;6(3):301-323.

42. Porru M, Zappavigna S, Salzano G, et al. Medical treatment of orthotopic glioblastoma with transferrin-conjugated nanoparticles encapsulating zoledronic acid. Oncotarget. 2014;5(21):10446-10459.

patient perspectives such as quality of life, adherence and satisfaction The manuscript management system is completely online and includes a very quick and fair peer-review system, which is all easy to use. Visit http://www.dovepress.com/testimonials.php to read real quotes from published authors. 